\title{
The Protective Effect of IL-6 Blockade on Glucose and Cardiovascular Risk in Patients with Active Rheumatoid Arthritis
}

\author{
ALEXANDRA JITARU ${ }^{1}$, ALEXANDRA MASTALERU ${ }^{1}$, ANDRA OANCEA ${ }^{1}$, \\ MADALINA ZOTA ${ }^{1}$, IRINA-MIHAELA ABDULAN ${ }^{1}$, CRISTINA POMIRLEANU ${ }^{1,3}$, \\ CODRINA ANCUTA ${ }^{1,3 *}$ FLORIN MITU ${ }^{1,2}$ \\ ${ }^{1}$ Grigore T. Popa University of Medicine and Pharmacy, Faculty of Medicine, 16 Universitatii Str., 700115, Iasi, Romania \\ ${ }^{2}$ Clinical Rehabilitation Hospital, Cardiovascular Rehabilitation Clinic, 14 Pantelimon Halipa Str., 700661, Iasi, Romania \\ ${ }^{3}$ Clinical Rehabilitation Hospital, $2^{\text {nd }}$ Rheumatology Clinic, 14 Pantelimon Halipa Str., 700661, Iasi, Romania
}

\begin{abstract}
Considering the multivalent role of interleukin-6 (IL-6) both in rheumatoid arthritis (RA) and in the metabolic processes, we aimed to evaluate the positive effect of subcutaneous tocilizumab (TCZ) on the probability of developing diabetes mellitus (DM). We recruited 56 consecutive patients with definite and active $R A$ and assessed demographics, RA-related parameters and metabolic biomarkers, including the Homeostasis Model Assessment for insulin resistance (HOMA-IR) and the Quantitative Insulin Sensitivity Check Index (QUICKI). After 52 weeks of treatment, most of the patients showed a statistically significant reduction of HOMA-IR $(3.61 \pm 1.21$ at baseline vs. $2.45 \pm$ 1.46 at the end of the study, $p<0.001)$, while QUICKI registered only a slight increase $(0.32 \pm 0.01$ at baseline vs. $0.33 \pm 0.01$ at final evaluation, $p<0.001)$. Our results strongly suggest that long-term IL-6 blockade has a beneficial effect in slowing the atherosclerotic process and reducing $C V$ risk in active $R A$.
\end{abstract}

Keywords: cardiovascular risk, insulin resistance, tocilizumab, metabolic parameters

\section{Introduction}

Rheumatoid arthritis (RA) is a chronic immune-inflammatory disease that associates high cardiovascular (CV) risk, mainly related to accelerated rate and a rapid progression of the atherosclerotic process [1]. Compared to the general population, the higher CV morbidity and mortality in RA patients is typically caused by an increased incidence of traditional risk factors (hypertension, diabetes, dyslipidemia, obesity, smoking, sedentary lifestyle) as well as by inflammatory mechanisms [1]. Generally, RA patients have a high incidence of metabolic syndrome [2] and one of the main components related to the disease activity is insulin resistance (IR), meaning a decreased response of the peripheral tissues to the metabolic effects of insulin [3]. IR is also one of the triggers for development of type 2 diabetes mellitus (DM), obesity and hypertension [4], with a 1.7fold increase in the risk of developing CV disease [3, 5].

Data about the relationship between RA and the presence of IR data are still contradictory. Some recent studies found no association between early RA and IR, while data reported from other studies showed that IR prevalence is higher in the initial stages of the disease [6-8]. The presence of IR in RA is associated with seropositivity [2], increased levels of tumor necrosis factor - alpha (TNF-alpha), interleukin-6 (IL-6), interleukin-1 (IL-1), interleukin-8 (IL-8) and perfectly related to high disease activity. Also, obese patients [2,9] and those undergoing glucocorticoid therapy have higher rates of IR $[4,7,8]$. Moreover, several studies already showed that anti-TNF therapy can improve IR in normal-weight patients with AR and IR [9]. 
However, IL-6 is a cytokine with different effects in modulation IR depending on the inflammatory status [10]. Thereby, in conditions associated with low grades of chronic inflammation (e.g. obesity and type 2 DM), IL-6 can determine IR [11]; many experimental studies in mice already showed a decrease in insulin sensitivity (IS) after the administration of high doses of IL-6, while blocking of this cytokine results in increased IS [12]. Because IL-6 is a major factor implicated especially in acute phase of inflammation, with an increase up to 1000-fold [13], it is legitimate to consider that adequate blockade of this molecule leads to a better regulation of the glucidic metabolism and the decrease of IR. However, there are only few studies evaluating the potential positive effect of anti-IL-6 agents (e.g Tocilizumab - TCZ) on IR in RA patients [14, 15].

Given the increased CV risk in RA, correlated with disease activity and associated systemic inflammation, as well as the multivalent role of IL-6 and interferences with metabolic processes, we aimed to evaluate the protective role of subcutaneous TCZ on the potential to develop DM and increase $\mathrm{CV}$ risk in patients with active AR.

\section{Materials and methods}

Study design

We performed a prospective observational 52-weeks study in 56 consecutive bio-experienced patients diagnosed with RA (fulfilling either the 1987 ACR criteria or the new 2010 ACR/EULAR classification criteria) [16], undergoing periodic treatment with subcutaneous TCZ according to local recommendation [17]. They were recruited from and followed-up in the outpatient Rheumatology 2 Department from the Clinical Rehabilitation Hospital in Iasi, Romania.

Patients were assessed according to a standard protocol, as follows: (i) demographics; (ii) RArelated parameters comprising clinical parameters (tender and swollen joint count on 28 evaluable joints, patient and physician global assessment on 0-10 Visual Analogue Scale - VAS), inflammatory (C-reactive protein - CRP, erythrocyte sedimentation rate - ESR) and immune tests (rheumatoid factor - RF, anti-cyclic peptide antibodies - ACPA), disease activity scores (Disease Activity Score - DAS28), as well as (iii) metabolic biomarkers including total cholesterol (TC) and fractions: high density lipoprotein (HDL)-cholesterol and low density lipoprotein (LDL)-cholesterol, triglycerides (TG), serum glucose (GLC) and insulin levels (Ins).

\section{Assessment of insulin resistance and sensitivity}

While hyperinsulinemic euglycemic clamp technique remains the gold standard for the evaluation of the IS, we found easier and noninvasive to use the Homeostasis Model Assessment for insulin resistance (HOMA-IR) and the Quantitative Insulin Sensitivity Check Index (QUICKI). We considered both HOMA-IR and QUICKI, although it is well known that the use of the QUICKI is superior to the HOMA-IR index, because the variables are logarithmically transformed [18].

Patients known with diabetes mellitus (DM) and those undergoing glucocorticoids were not included in the present study.

The study protocol was approved by the local ethics committee and patients signed the informed consent before recruitment.

\section{Statistical analysis}

Statistical analysis was done using STATA 12/SE (StataCorp, College Station, TX, USA), $p$-level under 0.05 being considered statistically significant. All results were reported as mean \pm standard deviation (SD); correlation of HOMA-IR and QUICKI at the onset and the end of the study was performed adjusting for age, sex and disease duration via estimation of the Pearson partial correlation coefficient (r). 


\section{Results and discussions}

\section{Baseline characteristics}

Demographics, RA-related data and metabolic parameters are shown in Table 1. We enrolled mainly women $(81.82 \%)$, with mean age of $61.51 \pm 11.1$ years and mean disease duration of $15.8 \pm$ 9.77 years. Up to $55 \%$ had RF positivity, while 27 (48.21\%) were ACPA positive. All patients had active disease with a DAS28-ESR of $4.07 \pm 1.45$ and DAS28-CRP of $3.38 \pm 1.01$.

The baseline mean level of TC was $229.47 \pm 39.29 \mathrm{mg} / \mathrm{dL}$, with increased levels of both of cholesterol fractions increased (mean HDL-cholesterol $65.8 \pm 21.34 \mathrm{mg} / \mathrm{dl}$ and LDL-cholesterol $133.45 \pm 48.62 \mathrm{mg} / \mathrm{dl})$. Also, the mean value of the serum glucose at the onset was $97.96 \pm 23.16$ $\mathrm{mg} / \mathrm{dl}$ (normal). Furthermore, mean value of HOMA-IR was $3.61 \pm 1.21 \mu \mathrm{U} \mathrm{mmol} / \mathrm{ml}$, indicating a significant IR, while the mean value for QUICKI was $0.32 \pm 0.01$, indicating a low IS.

Table 1. Baseline characteristics of the patients included in the study

\begin{tabular}{|c|c|}
\hline Women, n (\%) & $45(81.82)$ \\
\hline Age (years) mean $\pm \mathrm{SD}$ & $61.51 \pm 11.1$ \\
\hline Age at the time of disease onset (years) mean \pm SD & $45.53 \pm 13.93$ \\
\hline Disease duration (years) mean \pm SD & $15.8 \pm 9.77$ \\
\hline BMI $\left(\mathrm{kg} / \mathrm{m}^{2}\right)$, mean $\pm \mathrm{SD}$ & $28.04 \pm 5.8$ \\
\hline Smokers, n (\%) & $1(1.82)$ \\
\hline \multicolumn{2}{|l|}{ RA-related parameters } \\
\hline Tender joint count, mean \pm SD & $4.76 \pm 3.05$ \\
\hline Swollen joint count, mean \pm SD & $1.65 \pm 2.19$ \\
\hline $\mathrm{CRP}(\mathrm{mg} / \mathrm{l})$, mean $\pm \mathrm{SD}$ & $4.52 \pm 10.46$ \\
\hline $\mathrm{ESR}(\mathrm{mm} / \mathrm{h})$, mean $\pm \mathrm{SD}$ & $30.07 \pm 26.97$ \\
\hline RF positivity, n (\%) & $30(54.55)$ \\
\hline ACPA positivity, $\mathrm{n}(\%)$ & $27(48.21)$ \\
\hline DAS28-ESR, mean \pm SD & $4.07 \pm 1.45$ \\
\hline DAS28-CRP, mean \pm SD & $3.38 \pm 1.01$ \\
\hline \multicolumn{2}{|l|}{ Metabolic parameters } \\
\hline $\mathrm{TC}(\mathrm{mg} / \mathrm{dl})$, mean $\pm \mathrm{SD}$ & $229.47 \pm 39.29$ \\
\hline HDL-cholesterol $(\mathrm{mg} / \mathrm{dl})$, mean $\pm \mathrm{SD}$ & $65.8 \pm 21.34$ \\
\hline LDL-cholesterol $(\mathrm{mg} / \mathrm{dl})$, mean \pm SD & $133.45 \pm 48.62$ \\
\hline TG $(\mathrm{mg} / \mathrm{dl})$, mean $\pm \mathrm{SD}$ & $137.24 \pm 32.77$ \\
\hline GLC $(\mathrm{mg} / \mathrm{dl})$, mean $\pm \mathrm{SD}$ & $97.96 \pm 23.16$ \\
\hline Insulin $(\mu \mathrm{U} / \mathrm{ml})$, mean $\pm \mathrm{SD}$ & $14.82 \pm 2.68$ \\
\hline HOMA-IR $(\mu \mathrm{U} \mathrm{mmol} / \mathrm{ml})$, mean $\pm \mathrm{SD}$ & $3.61 \pm 1.21$ \\
\hline QUICKI, mean \pm SD & $0.32 \pm 0.01$ \\
\hline
\end{tabular}

RF, rheumatoid factor; ACPA, anti-citrullinated peptide antibodies; CRP, C-reactive protein; ESR, erythrocyte sedimentation rate; VAS, visual analog scale; DAS, disease activity score; BMI, body mass index; TC, total cholesterol; HDL, high density lipoproteins; LDL, low density lipoproteins; TG, triglycerides; GLC, serum glucose; HOMA-IR, homeostasis model assessment of insulin resistance; QUICKI, quantitative insulin sensitivity check index; SD, standard deviation.

\section{Efficacy data}

As a result of drug efficacy, we demonstrated a significant improvement in clinical and lab parameters, as well in disease activity score, after 52 weeks of treatment. The majority of patients reached moderate or low disease activity, as supported by statistically significant reduction of DAS28CRP and DAS28-ESR ( $p=0.0064$ and $p=0.0061$, respectively, $r=0.36$ ), indicating drug positive effects of s.c. tocilizumab (Table 2).

\section{TCZ influence on metabolic parameters}

As seen in Table 2, after 52 weeks of subcutaneous TCZ administration, we demonstrated a statistically significant reduction of IR (HOMA-IR: $3.61 \pm 1.21 \mu \mathrm{U} \mathrm{mmol} / \mathrm{mL}$ at baseline vs. $2.45 \pm$ $1.46 \mu \mathrm{Ummol} / \mathrm{mL}$ at the end of study, $p<0.001$ ), while the IS had only a slight but statistically significant increase (QUICKI $0.32 \pm 0.01$ at baseline $v s .0 .33 \pm 0.01$ at the end of the study, $p<0.001$ ). 
Table 2. Differences between baseline and final values of metabolic parameters and das 28

\begin{tabular}{|l|l|l|l|l|}
\hline \multicolumn{1}{|c|}{ Parameter } & $\begin{array}{l}\text { Baseline } \\
\text { mean } \pm \text { SD }\end{array}$ & \multicolumn{1}{c|}{$\begin{array}{l}\text { Final } \\
\text { mean } \pm \text { SD }\end{array}$} & $\boldsymbol{p}$ & $\boldsymbol{r}$ \\
\hline GLC $(\mathbf{m g} / \mathbf{d L})$ & $97.96 \pm 23.16$ & $99.52 \pm 26.74$ & $<0.001$ & 0.61 \\
\hline Insulin $(\boldsymbol{\mu U} / \mathbf{m L})$ & $14.82 \pm 2.68$ & $13.9 \pm 3.07$ & $<0.001$ & 0.83 \\
\hline HOMA-IR $(\boldsymbol{\mu U} \mathbf{~ m m o l / m L}$ & $3.61 \pm 1.21$ & $2.45 \pm 1.46$ & $<0.001$ & 0.71 \\
\hline QUICKI & $0.32 \pm 0.01$ & $0.33 \pm 0.01$ & $<0.001$ & 0.61 \\
\hline TC $(\mathbf{m g} / \mathbf{d L})$ & $229.47 \pm 39.29$ & $230.78 \pm 42.03$ & $<0.001$ & 0.62 \\
\hline TG $(\mathbf{m g} / \mathbf{d L})$ & $137.24 \pm 32.77$ & $135.38 \pm 34.62$ & 0.0011 & 0.43 \\
\hline DAS28-ESR & $4.07 \pm 1.45$ & $2.66 \pm 0.86$ & 0.0064 & 0.36 \\
\hline DAS28-CRP & $3.38 \pm 1.01$ & $2.34 \pm 0.7$ & 0.0061 & 0.36 \\
\hline
\end{tabular}

GLC, serum glucose; HOMA-IR, homeostasis model assessment of insulin resistance; QUICKI, quantitative insulin sensitivity check index; ESR, erythrocyte sedimentation rate; CRP, C-reactive protein; DAS, disease activity score; TC, total cholesterol; TG, triglycerides; SD, standard deviation.

Further, we assessed $\Delta$, the difference between the baseline and final values, and we calculated $\Delta$ for each parameter and for every patient included in the study.

\section{Relationship between HOMA-IR and disease variables}

We demonstrated a positive association of $\triangle$ HOMA-IR with BMI $(p<0.05), \Delta \mathrm{TC}(p<0.001)$ and $\Delta$ TG $(p<0.001)$, as well as with $\triangle \mathrm{DAS} 28$-CRP $(p=0.007)$ after 52 weeks of treatment with TCZ subcutaneously (Figures 1-3).

A strong correlation between the variation of IR (HOMA-IR) and the weight status (BMI) was reported, as shown by the follow-up tendency between the two polynomial trends, in Figure 1; therefore, the area marked is minimized on the group of patients, statistically supported by the afore mentioned $p$ value.

Similar results, with a stronger correlation, translated by a $p$ value that indicates a hypothesis error of $8 \%$, were demonstrated for the association between HOMA-IR and disease activity score (DAS28CRP); moreover, the IR decreases directly proportional with the disease activity after 52 weeks of subcutaneously TCZ administration (Figure 2).

Also, the reduction of IR is associated with a decrease in lipid markers values, as confirmed by Figure 3, indicating that TCZ indirectly diminish the CV risk. 


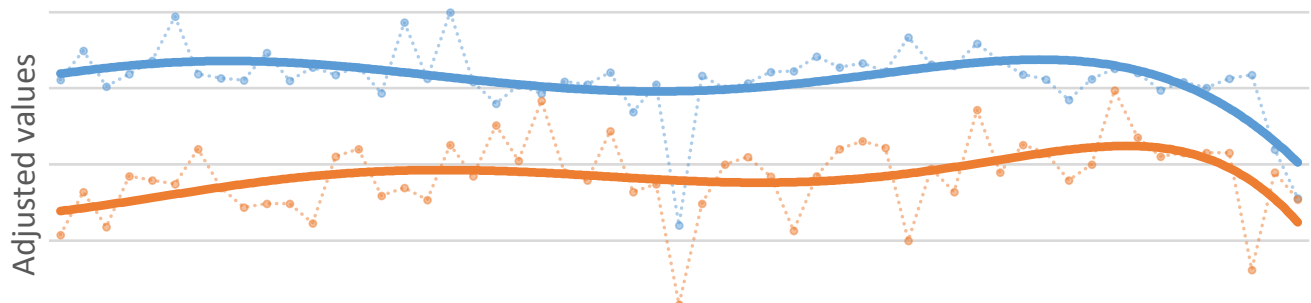

Patients

$\begin{array}{ll}\text { BMI polynomial trend } & \text { Adjusted BMI } \\ \text { BMOMA-IR polynomial trend }\end{array}$

Figure 1. $\triangle \mathrm{HOMA}-\mathrm{IR}$ variation according to BMIF

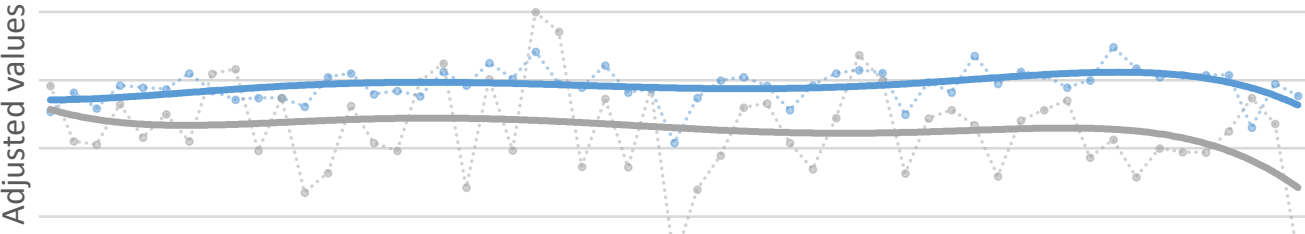

Patients

Adjusted $\triangle \mathrm{HOMA-IR}$
$\Delta \mathrm{HOMA}-\mathrm{IR}$ polynomial trend

Figure 2. Correlation between adjusted $\triangle H O M A-I R$ and $\triangle \mathrm{DAS} 28-\mathrm{CRP}$

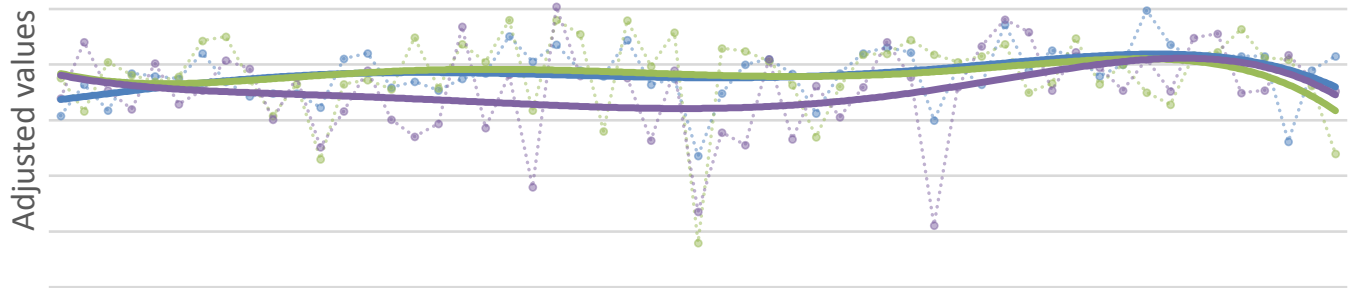

Patients
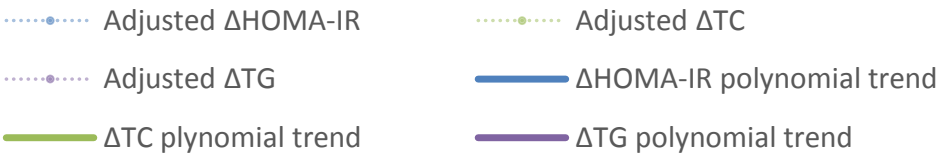

Figure 3. Correlation between adjusted $\Delta \mathrm{HOMA}-\mathrm{IR}, \Delta \mathrm{TC}$ and $\Delta \mathrm{TG}$

\section{Relationship between QUICKI and disease variables}


In regards to the relationship between QUICKI and the different variables assessed in our study, we demonstrated a positive association of $\Delta$ QUICKI with BMI $(p<0.001), \Delta \mathrm{TC}(p<0.001)$ and $\Delta$ TG $(p<0.001)$, as well as with $\triangle \mathrm{DAS} 28-\mathrm{CRP}(p<0.001)$ after undergoing 52 weeks of subcutaneous TCZ. These results are shown in Figures 4-6.

The positive correlation between the variation of IS (QUICKI) and the weight status (BMI) of the patients is demonstrated in figure 4, by the follow-up tendency between the two polynomial trends. Therefore, the area marked is minimized on the group of patients, statistically supported by the afore mentioned $p$ value.

Results with a similar correlation, translated by a $p$ value that indicates a hypothesis error of $1 \%$, are presented in figure 5 . The IS increases inversely proportional with the disease activity after 52 weeks of treatment. Thus, low disease activity has a positive impact on glucose metabolism.

The increase in IS leads to an improvement in the lipid profile markers and, indirectly in reducing CV risk, as shown in Figure 6.

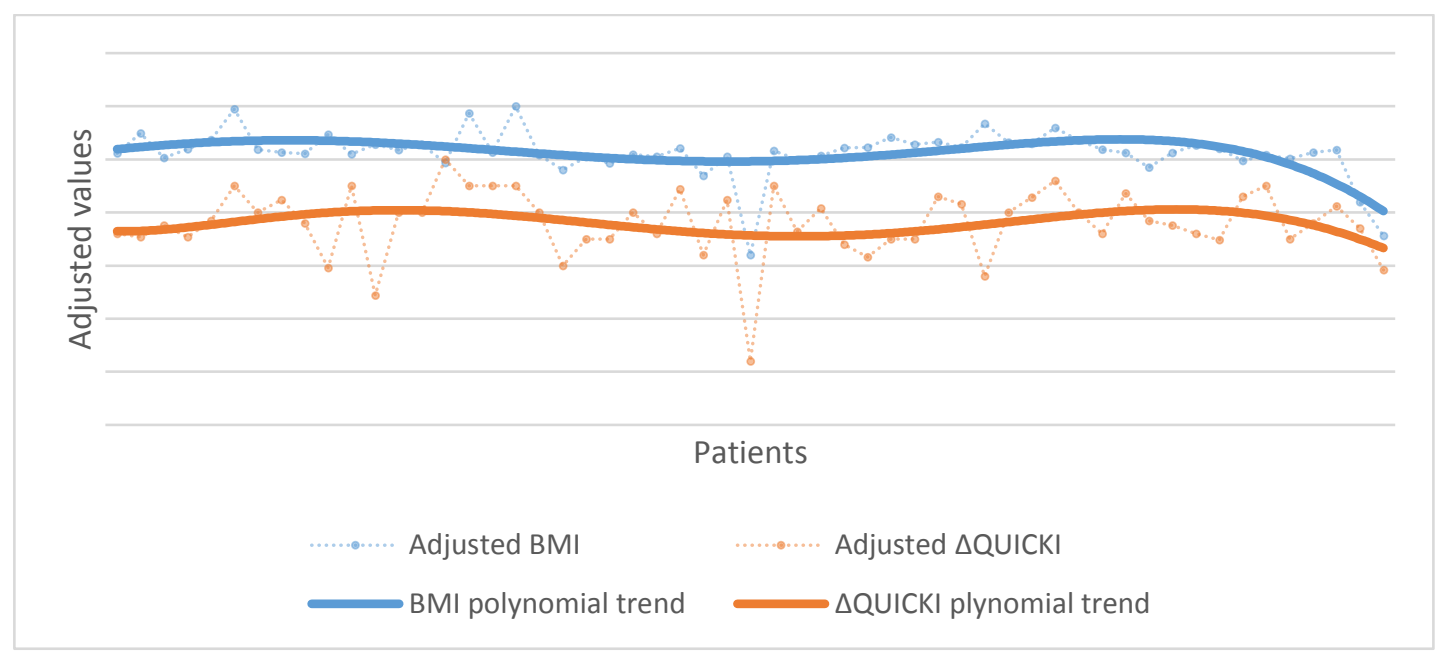

Figure 4. $\triangle \mathrm{QUICKI}$ variation according to BMI

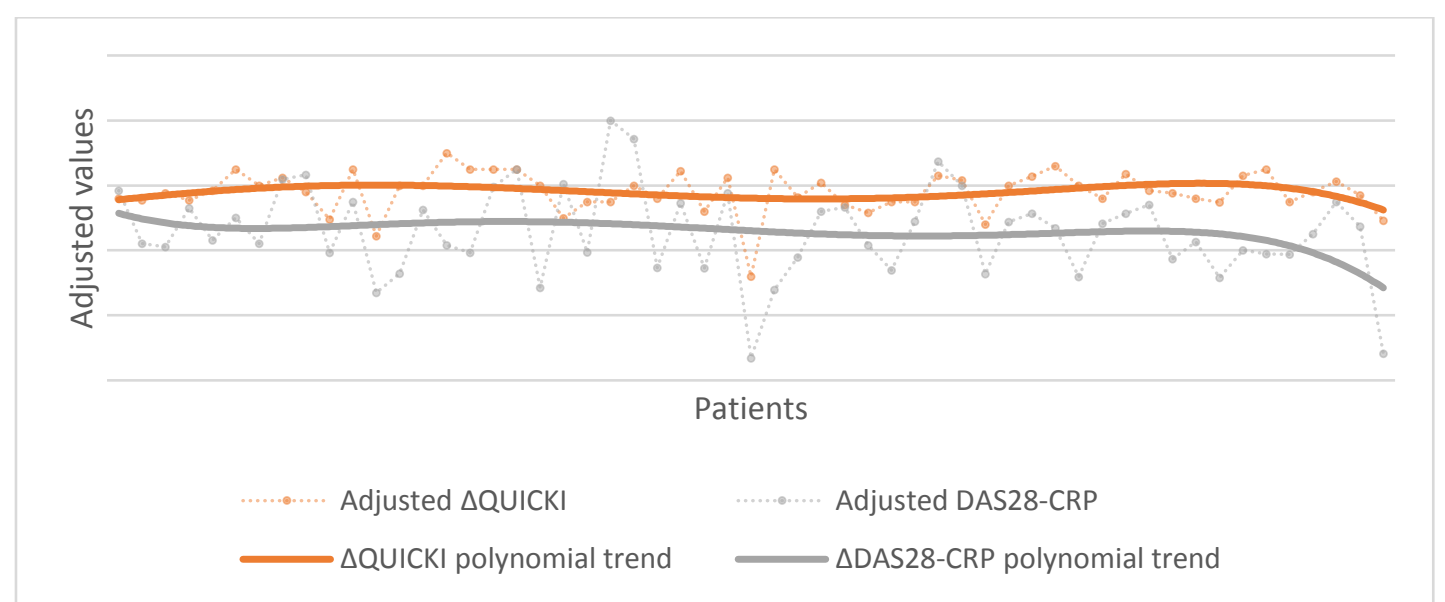

Figure 5. Correlation between adjusted $\triangle \mathrm{QUICKI}$ and $\triangle \mathrm{DAS} 28-\mathrm{CRP}$ 


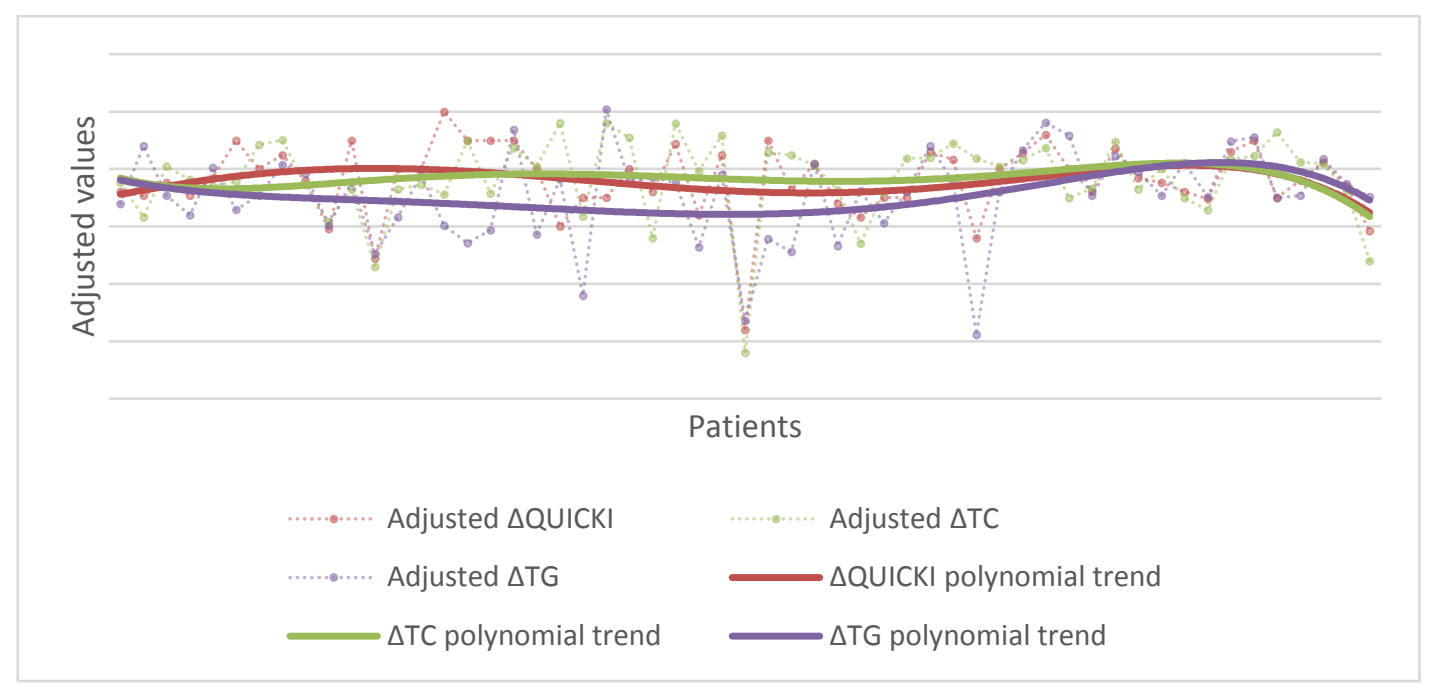

Figure 6. Correlation between adjusted $\Delta \mathrm{QUICKI}, \Delta \mathrm{TC}$ and $\Delta \mathrm{TG}$

We performed a prospective study in a cohort of 56 consecutive active RA who underwent subcutaneous TCZ therapy, aiming to investigate the influence of anti-IL- 6 blockade on glucose level and the latent DM. The premise we started from was that TCZ decreases insulin resistance.

A close interrelation between inflammation and IR was lately advanced and extensively studied in RA in recent years. Interestingly, the study performed by Dessein et al. (2003) has demonstrated that the acute phase response in RA patients is strongly associated with the decrease in IS [19]. The insulin production in these patients as well as those known with other inflammatory arthritis appears to be $57 \%$ higher than in age and sex-matched controls [20]. In a similar study, Ferraz-Amaro et al. (2018) showed insulin levels were $33 \%$ higher in a cohort of 151 patients with RA as compared to healthy controls and $41 \%$ higher than in age and sex-matched controls [21]. Moreover, a longstanding persistent inflammatory status represents an early step in the atherogenic process in RA, due to IR and endothelial dysfunction [22].

Because of the efficacy of TCZ on systemic inflammation in patients with active RA, it is legitimate to consider the potential positive effect on the pathways related to IR and atherosclerosis in RA. Chung et al. (2008) successfully confirmed that HOMA-IR was significantly correlated and directly proportional with IL-6 levels in active RA patients [23].

However, only a few studies revealed the effect of the blocking IL-6 on the glucose metabolism. A study published in 2019 by Liao et al. [24] demonstrated the rapid and important decrease in IR after intravenous administration of TCZ for the treatment of active and severe RA. This positive effect was more obvious and associated with an important increase of IS in the group of patients with more severe IR at baseline. Also, Liao and his team showed that ESR levels were strongly and significantly related to HOMA-IR index in patients receiving TCZ. These results were further supported by the negative correlation between the baseline ESR levels and QUICKI index, before and after the TCZ infusion.

Schultz et al. (2010) studied IS in 11 non-diabetic RA patients receiving treatment with intravenous TCZ at a dose of $8 \mathrm{mg} / \mathrm{kg}$ every 4 weeks and found a significant decrease in HOMA-IR after 3 months of therapy [25].

Also, Chen et al. (2015) performed a study on 24 patients with RA treated with intravenous TCZ at a dose of $4 \mathrm{mg} / \mathrm{kg}$ once monthly for the first 3 months followed by $8 \mathrm{mg} / \mathrm{kg}$ monthly for the rest of the study. Their results showed a significant reduction in HOMA-IR in short-term (24 weeks) $(2.97 \pm 0.38$ vs. $1.99 \pm 0.25 ; p<0.05)[26]$.

Recent studies compared the IR levels between RA and non-RA groups, based on relevant characteristics; the results revealed that RA patients with features atypical for IR (i.e., normal or low BMI) had higher levels of HOMA-IR compared with control-group with similar characteristics [27]. 
Regarding the markers of glucose and lipid metabolism considered in our study, BMI was the strongest predictor of IS, while HOMA-IR was more likely to be associated with the lipid levels. We appreciate that our results are relevant for the Romanian medical practice, although the study has several limits: the number of patients, the short period of follow-up, the classic evaluation of lipid and glucose metabolism and the absence of a control group. Further studies are needed in larger cohorts of RA patients, with a more complex evaluation of the glucose metabolism (i.e., glycated hemoglobin).

\section{Conclusions}

The results of our study confirm the positive effect of TCZ on glucose metabolism in patients with active RA, supporting that the long-term inhibition of IL-6 might be of great benefit in slowing of the atherosclerotic process and reducing $\mathrm{CV}$ risk.

Aknowledgements: We thank Mr. Cezar Chițac for supporting us with the statistics.

\section{References}

1. HUMPHREYS, J.H., WARNER, A., CHIPPING, J., MARSHALL, T., LUNT, M., SYMMONS, D.P. and VERSTAPPEN, S.M., Arthritis Care Res (Hoboken), 66, no 9, 2014, p. 1296 - 1301.

2. NICOLAU, J., LEQUERRE, T., BACQUET, H. and VITTECOQ, O., Joint Bone Spine, 84, no 4, 2017, p. $411-416$.

3. DE FRONZO, R.A., Neth J Med, 50, no 5, 1997, p. $191-197$.

4. MANRIQUE-ARIJA, S., URENA, I., VALDIVIELSO, P., RIOJA, J., JIMENEZ-NUNEZ, F.G., IRIGOYEN, M.V. and FERNANDEZ-NEBRO, A., Clin Rheumatol, 35, no 1, 2016, p. 43 - 53.

5. SHAHIN, D., ELTORABY, E., MESBAH, A., and HOUSSEN, M., Clin Biochem, 43, no. 7-8, 2010, p. $661-665$.

6. MIRJAFARI, H., FARRAGHER, T.M., VERSTAPPEN, S.M., YATES, A., BUNN, D., MARSHALL, T., LUNT, M., SYMMONS, D.P. and BRUCE, I.N., Arthritis Res Ther, 13, no 5, 2011, R159.

7. EL-HINI, S.H., MOHAMED, F.I., HASSAN, A.A., ALI, F., MAHMOUD, A. and IBRAHEEM, H.M., Rheumatol Int, 33, no. 9, 2013, p. 2283 - 2289.

8. WASKO, M.C., KAY, J., HSIA, E.C. and RAHMAN, M.U., Arthritis Care Res (Hoboken), 63, no. 4, 2011, p. 512 - 521.

9. ABOUASSI, H., TUNE, K.N., GILMORE, B., BATEMAN, L.A., MCDANIEL, G., MUEHLBAUER, M., HUEBNER, J.L., HOENIG, H.M., KRAUS, V.B., ST CLAIR, E.W., KRAUS, W.E. and HUFFMAN, K.M., J Rheumatol, 41 no 10, 2014, p 1974 - 1979.

10. TANAKA, T., NARAZAKI, M. and KISHIMOTO, T., Cold Spring Harb Perspect Biol, 6, no 10, 2014, a016295.

11. DONATH, M.Y., Nat Rev Drug Discov, 13, 2014, p 465 - 476.

12. KRAAKMAN, M.J., ALLEN, T.L., WHITHAM, M., ILIADES, P., KAMMOUN, H.L., ESTEVEZ, E., LANCASTER, G.I. and FEBBRAIO. M.A., Diabetes Obes Metab, 15, 2013, p 170 175.

13. SPROSTON, N.R., ASHWORTH, J.J., Front Immunol, 9, 2018, p 754.

14. GONZ'ALEZ-GAY, M.A., LLORCA, J., GONZ'ALEZ-JUANATEY, C. and DESSEIN, P.H., Arthritis Rheum, 67, no. 9, 2015, p. 2548 - 2550.

15. GILES, J.T., DANIELIDES, S., SZKLO, M., POST, W.S., BLUMENTHAL, R.S., PETRI, M., SCHREINER, P.J., BUDOFF, M., DETRANO, R. and BATHON, J.M., Arthritis Rheum, 67, no. 3, 2015, p. $626-636$.

16. NAM, J.L., TAKASE-MINEGISHI, K., RAMIRO, S., CHATZIDIONYSIOU, K., SMOLEN, J.S., VAN DER HEIJDE, D., BIJLSMA, J.W., BURMESTER, G.R., DOUGADOS, M., SCHOLTE- 
VOSHAAR, M., VAN VOLLENHOVEN, R. and LANDEWÉ, R., Ann Rheum Dis, 76, no 6, 2017, p. 1113 - 1136.

17. ***Protocol terapeutic in artrita reumatoida privind utilizarea agentilor biologici adalimumabum (original si biosimilar), certolizumabum, etanerceptum (original si biosimilar), golimumabum, infliximabum (original si biosimilar), tocilizumabum, rituximabum, 2019, p. 164-180.

18. KHAN, S.H., KHAN, A.N., CHAUDHRY, N., ANWAR, R., FAZAL, N. and TARIQ, M., Diabetol Metab Syndr, 14, no 11, 2019, p. 44.

19. DESSEIN, P.H., JOFFE, B.I. and STANWIX, A.E., J Rheumatol, 30, 2003, p. 1403 - 1405.

20. DESSEIN, P.H., JOFFE, B.I., STANWIX, A., BOTHA, A.S. and MOOMAL, Z., J Rheumatol, 24, 2002, p. 462 - 466.

21. FERRAZ-AMARO, I., LÓPEZ-MEJIAS, R., TEJERA-SEGURA, B., DE VERA-GONZÁLEZ, A.M., UBILLA, B., OLMOS, J.M., HERNANDEZ, J.L. and GONZÁLEZ-GAY, M.A., Clin Exp Rheumatol, 36, no 3, 2018 p. 421 - 427.

22. MANAVATHONGCHAI, S., BIAN, A., RHO, Y.H., OESER, A., SOLUS, J.F., GEBRETSADIK, T., SHINTANI, A. and STEIN, C.M., J Rheumatol, 40, no 11, 2013, p. 1806 - 1811.

23. CHUNG, C.P., OESER, A., SOLUS, J.F., GEBRETSADIK, T., SHINTANI, A., AVALOS, I., SOKKA, T., RAGGI, P., PINCUS, T. and STEIN, C.M., Arthritis Rheum, 58, no 7, 2008, p. 2105 2112.

24. LIAO, K.P. and SOLOMON, D.H., Rheumatology, 52, no 1, 2013, p. 45 - 52.

25. SCHULTZ, O., OBERHAUSER, F., SAECH, J., RUBBERT-ROTH, A., HAHN, M., KRONE, W. and LAUDES, M., PLoS One, 5, no 12, 2010, e14328.

26. CHEN, D.Y., CHEN, Y.M., HSIEH, T.Y., HSIEH, K.W., LIN, C.C. and LAN, J.L., Arthritis Res Ther, 17, 2015, p. 52

27. CASTAÑEDA, S., REMUZGO-MARTINEZ, S., LOPEZ-MEJIAS, R., GENRE, F., CALVOALEN, J., LLORENTE, I., AURRECOECHEA, E., ORTIZ1, A.M., TRIGUERO, A., BLANCO, R., LLORCA, J. and GONZALEZ-GAY, M.A., Clin Exp Rheumatol, 37, no 3, 2019, p. 465 - 473.

Manuscript received: 10.02 .2020 